\title{
RESISTANT STARCH AND BIOACTIVE CONTENTS OF UNRIPE BANANA FLOUR AS INFLUENCED BY HARVESTING PERIODS AND ITS APPLICATION
}

\author{
Anuchita Moongngarm, Wanassanun Tiboonbun, Mai Sanpong, Pimpila Sriwong, \\ Laongdao Phiewtong, Rattanapon Prakitrum and Nattipon Huychan \\ Department of Food Technology and Nutrition, Faculty of Technology, \\ Mahasarakham University, Mahasarakham 44150, Thailand
}

Received 2014-07-10; Revised 2014-07-15; Accepted 2014-08-09

\begin{abstract}
Recently, various innovative products from unripe banana flour have been reported as it is high in resistant starch and other important compounds. The harvesting period of the unripe banana fruit is one of the key factors affecting the quality of the unripe banana flour in terms of resistant starch and bioactive compound content. The study aimed to investigate the effect of the harvesting stages of unripe banana fruit on Resistant Starch (RS) content, carotenoid content, antioxidant activity and the application of unripe banana flour to prepare high RS rice noodle. Four different harvesting stages of banana fruits of Musa sapientum Linn including 75, 90, 105 and 120 days after bloom, were processed for banana flours. The results indicated that the maturation stages affected RS, some bioactive contents, antioxidant activities. The highest RS content $(48.88 \%)$ of banana flour was obtained from the 105 day banana fruits. The total phenolic and carotenoid contents were high in the banana flours harvested between 75 and 105 days. The unripe banana flour could be substituted for rice flour as high as $80 \%$ and contained RS content as high as $18.64 \%$ whereas the commercial rice noodle had $4.21 \%$ of RS content. Therefore, the preparation of unripe banana flour from banana fruit harvested at 105 days and applying it in the preparation of functional food is promising.
\end{abstract}

Keywords: Green Banana, Resistant Starch, Antioxidant Activity, Unripe Banana

\section{INTRODUCTION}

Banana (Musa sapientum, ABB group) is one of the most popular and consumed fruits in Thailand. It is equally popular in other parts of the world especially in tropical regions. It is a climacteric fruit, generally consumed in a ripe state; consequently, a large amount of ripe bananas are lost during commercialization. They are quickly perishable and if the processes of harvesting, handling and transporting are not done properly, the bananas will soon decompose and become unwholesome for human consumption. Even though estimations of production losses in each country are difficult, some establishment put losses of bananas as high as half of the total number grown. Reduction in this loss economically would be of great significance to growers and consumers. To lessen the loss, any economical processing method that increases the utilization of banana is accepted. One of the most interesting processing methods is the production of unripe (green) banana flour and the incorporation of that flour into various food products. Due to the high content of these functional ingredients, regular consumption of unripe banana flour can be expected to give health benefits (Rodríguez-Ambriz et al., 2008). The advantages of unripe banana flour are, high in resistant starch (42\%)

Corresponding Author: Anuchita Moongngarm, Department of Food Technology and Nutrition, Faculty of Technology, Mahasarakham University, Mahasarakham 44150, Thailand 
(Ovando-Martinez et al., 2009; Rodriguez-Amaya and Kimura, 2004) and dietary fiber content (14.5\%) (Alkarkhi et al., 2011). Recently, some innovative products from unripe banana flour have been reported, such as slowly digestible cookies (Juarez-Garcia et al., 2006). RS, by definition, is a part of the starch that is not broken down by enzymes in the small intestine. It enters the large intestine where it is partially or wholly fermented by microorganisms. RS is generally considered to be one of the components that makeup Total Dietary Fiber (TDF) (Ovando-Martinez et al., 2009).

In the production of unripe banana flour, one of the key factors in obtaining the highest quality in terms of achieving the highest amount of RS is the quality of the unripe banana fruit. In this study, it was hypothesized that the stages of maturation would affect the level of RS and also other key quality factors of the obtained flour. Therefore, it became important to investigate harvesting at the right maturity stage. By knowing the stage of maturation of the bananas, it would be possible to plan harvesting, handling, processing and marketing operations efficiently. Proper estimation of the maturity stage of the banana is important for unripe banana flour usage.

Therefore, the present study was carried out to investigate the effect of the maturation (harvesting period) on RS content, carotenoid content and antioxidant activity. Moreover, unripe banana flour was applied in the preparation of rice noodle because this type of noodle is popularly consumed in Asian countries and a large amount of it is manufactured. Our previous study (Tiboonbun et al., 2011) prepared high RS content rice noodle using unripe banana flour. In that study, several aspects of noodle qualities such as tensile strength, cooking loss and color of noodle were determined but sensorial observations were not included. Therefore, the present study was conducted to evaluate the acceptability of panelists and to confirm the potential use of unripe banana flour for the production of high RS rice noodle as a functional food.

\section{MATERIALS AND METHODS}

\subsection{Banana Fruit Sample}

Approximately nine bunches of unripe banana fruits (Musa sapientum, ABB group, Kluai Nam Wa) were collected from a commercial grower in the Muang district, Mahasarakham province, Thailand. The maturation stages were tacked after the bunch emergence and the fruits were collected on harvesting day on the 75, 90, 105 and 120 day. Three bunches (approximately, 9-12 hands) of each stage were served as three replicates. All fruits from all hands in each bunch were mixed as one replicate, except wing fruits that were removed from the hands. The fruits were weighed and then washed before their peel was separated. The unripe banana flour was prepared according to Tribess et al. (2009) with some modifications. The pulps were cut into transverse slices of about $0.2 \mathrm{~cm}$ thickness and soaked in $0.5 \%$ $(\% \mathrm{w} / \mathrm{v})$ citric acid solution for $15 \mathrm{~min}$, to prevent enzymatic browning. After that, the solution was drained and the banana slices were dried in a tray dryer at $45-50{ }^{\circ} \mathrm{C}$ until the moisture content reached approximately $10 \%$. The dried pulp slices were ground using a coffee grinder and passed through 70 mesh screens to attain the unripe banana flour. The flours were stored in airtight plastic packs in cold storage $\left(4^{\circ} \mathrm{C}\right)$ until used.

\subsection{Determination of Physical Characteristics of Banana Fruits}

The peel color of the banana fruits was judged visually using the $7^{\circ} \mathrm{C}$ color scale (Dadzie and Orchard, 1997), where 1 = full unripe, 2 = unripe with yellow tip, $3=$ more unripe than yellow, $4=$ more yellow than unripe, $5=$ yellow with unripe tip, $6=$ fully yellow, $7=$ yellow with black spots. The banana was considered unripe at stages 1-4 and ripe at stages 5-7. They were then weighed using a weighing balance. The $\mathrm{pH}$ of the unripe banana fruit was measured using a $\mathrm{pH}$ meter. Pulp suspension $(8 \%(\mathrm{w} / \mathrm{v}))$ was stirred for $5 \mathrm{~min}$, allowed to stand for $30 \mathrm{~min}$, filtered and the $\mathrm{pH}$ of the filtrate measured (Suntharalingam and Ravindran, 1993). Total acidity in the same slurries was measured using the titration method. Titratable acidity expressed as malic acid (\%) (AOAC, 2000). Reducing sugar content was measured using the method of (Somogyi, 1952).

\subsection{Determination of Resistant Starch (RS), Non-RS and Total Starch (TS)}

Prior to determining chemical compositions, the moisture content of the samples was measured using the drying method of the (AOAC, 2000). The solubilized starch (non-RS), RS and total starch were determined using the enzymatic and spectrophotometric method using the Megazyme resistant starch and total starch assay kit (Megazyme International Ireland Ltd, Bray, Ireland). 


\subsection{Determination of Carotenoids}

\subsubsection{Total Carotenoid Content}

The total carotenoids were evaluated using the method reported by (Rodriguez-Amaya and Kimura, 2004).

\subsection{2. $\beta$-Carotene Determination}

Sample preparation and $\beta$-carotene determination were done using the method of (Barua and Olson, 1998) with some modifications. An aliquot of $20 \mu \mathrm{L}$ was injected onto the HPLC system (Spectra Physic SP 800 UV detector, Phenomenex column, reverse phase C18, 4 $\mu \mathrm{m} 4.6 \times 150 \mathrm{~mm}$, USA). The gradient elution at ambient temperature was used. The mobile phases applied were methanol and water. The gradient of methanol-water (90: 10) at a flow rate of $1.2 \mathrm{mlmin}^{-1}$ was changed linearly over 10 min to $100 \%$ methanol, then $100 \%$ methanol was continued for $35 \mathrm{~min}$ and finally methanol-water (90:10) again for $5 \mathrm{~min}$. Peaks were quantified at $450 \mathrm{~nm}$ using a freshly-prepared standard curve in an extraction buffer and identified on the basis of their characteristic absorption spectra. Retention times relative to known standards were available. Results were expressed as $\mu \mathrm{g}_{100 \mathrm{~g}^{-1}}$ dry weight.

\subsection{Determination of Antioxidant Activity}

\subsubsection{Sample Extraction}

The banana flour samples $(5.0 \mathrm{~g})$ were shaken with $25 \mathrm{~mL}$ of $80 \%$ methanol at room temperature for $3 \mathrm{~h}$. The extracts were filtered through Whatman No. 1 paper, each of the filtrates was concentrated using a rotary evaporator at $40^{\circ} \mathrm{C}$ and the weight of each extract was recorded before being re-dissolved with methanol to a final volume of $25 \mathrm{ml}$ in a volumetric flask. The extracts were used for antioxidant analyses (Dasgupta and De, 2004).

\subsubsection{Total Phenolic Compounds (TPC)}

The TPC was determined by Folin-Ciocalteu reagent and expressed as milligram (mg) of Gallic Acid Equivalents (GAE) per gram (g) of dry weight basis of the extract (Kim et al., 2006).

\subsubsection{DPPH Radical Scavenging Activity}

The antioxidant capacity of the extracts was evaluated on the basis of the radical scavenging capacity of the radical DPPH radical by following the method described by (Dasgupta and De, 2004). The percent inhibition activity was calculated as: $\left[\left(1-\mathrm{A}_{\text {sample }}\right) / \mathrm{A}_{\text {control }}\right]$ $\times 100$, where A was the absorbance of using the sample or control. BHA and gallic acid were used as the positive controls. The percentage of scavenging activity (inhibition) from a different concentration was plotted against the sample concentration to obtain $\mathrm{IC}_{50}$, defined as the concentration of sample necessary to cause $50 \%$ inhibition (Moongngarm and Komphiphatkul, 2011).

\subsubsection{Hydroxyl Radical Scavenging Activity}

The effect of the hydroxyl radical was assayed by using the 2-deoxyribose oxidation method (Sakanaka et al., 2005). Percent inhibition of deoxyribose degradation by the hydroxyl radical was calculated as: [(1-A sample $) / A$ control] $\times 100$, where $\mathrm{A}$ was the absorbance of using the sample or control. BHA and gallic acid were used as the positive controls. The hydroxyl radical scavenging activity of the sample was expressed as the $\mathrm{IC}_{50} \mu \mathrm{g} \mathrm{mL}$ (Moongngarm and Komphiphatkul, 2011).

\subsubsection{Lipid Peroxidation Assay}

Lipid peroxidation was used to measure the lipid peroxide formed in egg yolk homogenate as lipid-rich media (Dasgupta and De, 2004). Inhibition of lipid peroxidation was expressed as $\mathrm{IC}_{50}$ values.

\subsection{Preparation of Rice Noodle}

The preparation of rice noodle was done by following the method of (Tiboonbun et al., 2011). The basic ingredients of rice noodle were $28.06 \mathrm{~g}$ rice flour $(100 \%$ rice flour or $0 \%$ substitution, served as control sample), 0 $\mathrm{g}$ unripe banana flour, $7.42 \mathrm{~g}$ cassava flour, $64.08 \mathrm{~g}$ water and $0.44 \mathrm{~g}$ vegetable oil. Five additional rice noodle samples were prepared by substituting rice flour with 20, 40,60, 80 and $100 \%$ banana flour (prepared from 105 days banana fruits). The rice noodle was prepared by mixing flour with water; approximately 100 $\mathrm{ml}$ of flour slurry was poured into a tray $(20 \times 30 \mathrm{~cm})$ and steamed for $5 \mathrm{~min}$. The cooked rice sheet was cooled down to room temperature before being cut into $2.5 \times 30$ $\mathrm{cm}$ strips to obtain a fresh noodle.

\subsection{Sensory Evaluation}

Fresh noodle samples were prepared for sensory evaluation. The samples were boiled in water for one minute, then stored at $45-50^{\circ} \mathrm{C}$ for not more than $20 \mathrm{~min}$ in tightly covered plastic food containers prior to testing and serving with soup. The noodle was evaluated for appearance, flavor, taste, texture, adhesiveness and overall liking by 30 untrained panelists using the 9-point hedonic scales, where $9=$ extremely like and $1=$ 
extremely dislike. Each panelist evaluated six samples (identified by unique three-digit codes) in a balanced sequential order. The optimal ratio of banana flour to rice flour in the noodles was investigated using sensory qualities in comparison to the control noodles.

\subsection{Statistic Analysis}

All results of triplicate samples were statistically analyzed using SPSS (Demo version) for windows. The results of individual samples are reported as the mean \pm standard deviation. The Duncan's Multiple Range Test (DMRT) was applied for mean comparison when analysis of variance showed significant differences at a 95\% confidence level.

\section{RESULTS}

\subsection{Physical Characteristics of Banana Fruits}

The peel color of unripe banana fruits harvested from 75 to 105 days was unripe (maturation stage 1 and 2) while those collected at 120 days were also unripe but yellow trace was observed and judged as stage 2 and 3 (Table 1). All banana fruit samples in this study were unripe according to a 7-degree color scale used as the reference for color measurements guiding that green banana from maturation stage 1 to 4 are unripe banana. The maturation stages of banana depend on cultivars.

The fruit weight ranged from 88.76 to $139.47 \mathrm{~g}$, which was the smallest weight observed in fruits at 75 days. The biggest fruits were found in fruits at 120 days. The $\mathrm{pH}$ values and total acidity of the banana flour from all stages were not significantly different. The $\mathrm{pH}$ raged between 5.39 and 5.41 and the total acidity varied from 0.60 to $0.64 \%$ (Table 1). These limited variations may be because the banana fruit used in this study was unripe; therefore the change was too small and undetectable. The level of reducing sugar in banana flour prepared from 120 day banana fruits was higher $\left(5.09 \mathrm{mg} \mathrm{g}^{-1}\right)$ than that of the flour prepared from fruits harvested between 75 and 105 days (3.72$3.96 \mathrm{mg} \mathrm{g}^{-1}$ ). The increase of reducing sugar is caused by starch degradation during the ripening stage.

\subsection{Resistant Starch, Total Starch (TS) and Non-RS Contents}

The RS of unripe banana flour varied from 32.26 to $48.88 \%$. The highest content was in the flour obtained from unripe banana collected at 105 days, whereas the lowest RS content was in unripe banana flour from fruits harvested at 120 days (Table 2).

\subsection{Total Carotenoids and $\beta$-Carotene}

The concentration of total carotenoids and $\beta$-carotene are explained in Table 3. The maturation stages in this study did not significantly affect the concentration of $\beta$ carotene, but total carotenoids. The total carotenoids varied from 826.24 to $1054.58 \mu \mathrm{g} 100 \mathrm{~g}^{-1}$ dry weight whereas the $\beta$-carotene content ranged 415.38 to 574.90 $\mu \mathrm{g} 100 \mathrm{~g}^{-1}$ dry weights.

\subsection{Antioxidant Activities}

The results of Total Phenolic Compound (TPC) were expressed as Gallic Acid Equivalent (GAE) as shown in Table 3. The unripe banana flours from 75 to 105 days had a significantly higher level of TPC (3.23-3.48 mg $\mathrm{GAEg}^{-1}$ ) while TPC from flour of banana 120 days was reduced to $2.59 \mathrm{mg} \mathrm{GAEg}^{-1}$. The concentration of TPC in this study was slightly different compared with the report of (Bennett et al., 2010), who found that the TPC of banana (Terra cultivar) was $6.50-9.90 \mathrm{mgg}^{-1}$. This may due to the variation of varieties, growing season, postharvest treatment and growing management.

The unripe banana flours prepared from bananas collected at 75 and 90 days showed good antioxidant activity when evaluated with DPPH radical scavenging capacity and the lipid peroxidation assay, whereas flours from banana fruits collected at 90 and 105 days indicated good antioxidant activity when evaluated through the hydroxyl radical scavenging method (Fig. 1). This may be due to the variation of the distribution of bioactive compounds that possess antioxidant in different stages of maturation. At the earlier stages (75-105 days), bananas contained a higher level of total phenolic, which may cause the banana flour to have stronger antioxidant activity than the banana at 120 days.

\subsection{Rice Noodle Quality}

\subsubsection{RS, Solubilized Starch (Non-RS) and TS Contents of Rice Noodle}

An increase in RS content was observed in rice noodle that substituted for unripe banana flour (Table 4). The control ( $0 \%$ of banana flour) had the lowest RS content $(4.21 \%)$, whilst the rice noodle containing $100 \%$ of unripe banana flour had the significantly highest RS content $(18.64 \%)$. This is related to the high RS content of unripe banana flour used $(48.88 \%)$ (Table 2). 
Table 1. Physical characteristics of banana fruits obtained from different harvesting stages

\begin{tabular}{llclll}
\hline $\begin{array}{l}\text { Harvesting } \\
\text { period (days) }\end{array}$ & Peel color (stage) & Fruit weight $(\mathrm{g})$ & $\mathrm{pH}$ & Total acidity $(\%)$ & $\begin{array}{c}\text { Reducing sugars } \\
\left(\mathrm{mg} \mathrm{g}^{-1}\right)\end{array}$ \\
\hline 75 & Unripe (1) & $88.76 \pm 7.09^{\mathrm{c}}$ & $5.40 \pm 0.09$ & $0.64 \pm 0.02$ & $3.72 \pm 0.25^{\mathrm{b}}$ \\
90 & Unripe (1) & $109.52 \pm 8.82^{\mathrm{b}}$ & $5.39 \pm 0.08$ & $0.61 \pm 0.06$ & $3.96 \pm 0.23^{\mathrm{b}}$ \\
105 & Unripe (1-2) & $136.59 \pm 12.1^{\mathrm{a}}$ & $5.41 \pm 0.02$ & $0.63 \pm 0.01$ & $3.89 \pm 0.80^{\mathrm{b}}$ \\
120 & Unripe, with yellow trace (2-3) & $139.47 \pm 15.6^{\mathrm{a}}$ & $5.39 \pm 0.07$ & $0.60 \pm 0.04$ & $5.09 \pm 0.26^{\mathrm{a}}$ \\
\hline
\end{tabular}

$\overline{a, b, c}$ Means within a column with different superscripts are significantly different $(\mathrm{p} \leq 0.05)$

Table 2. Resistant Starch (RS), Total Starch (TS), and non-RS of unripe banana flour obtained from banana fruits harvested at different maturation stages

\begin{tabular}{llll}
\hline Harvesting period (days) & RS $(\%)$ & TS $(\%)$ & Non-RS $(\%)$ \\
\hline 75 & $44.89 \pm 2.16^{\mathrm{b}}$ & $69.18 \pm 1.15^{\mathrm{c}}$ & $24.29 \pm 1.89^{\mathrm{b}}$ \\
90 & $45.25 \pm 3.37^{\mathrm{b}}$ & $72.63 \pm 0.48^{\mathrm{b}}$ & $27.38 \pm 3.25^{\mathrm{b}}$ \\
105 & $48.88 \pm 2.05^{\mathrm{a}}$ & $75.74 \pm 1.21^{\mathrm{a}}$ & $26.86 \pm 1.32^{\mathrm{b}}$ \\
120 & $32.26 \pm 2.54^{\mathrm{c}}$ & $68.60 \pm 1.07^{\mathrm{c}}$ & $36.34 \pm 2.11^{\mathrm{a}}$ \\
\hline $\mathrm{a}, \mathrm{b}, \mathrm{c}$
\end{tabular}

$\overline{\mathrm{a}, \mathrm{b}, \mathrm{c}}$ Means within a column with different superscripts are significantly different $(\mathrm{p} \leq 0.05)$

Table 3. Total phenolic, $\beta$-carotene, and total carotenoid contents of unripe banana flour obtained from banana fruits harvested at different maturation stages

\begin{tabular}{llll}
\hline Harvesting period (days) & $\begin{array}{l}\text { Total phenolic content } \\
\left(\mathrm{mg} \mathrm{GAEg}^{-1}\right)\end{array}$ & $\begin{array}{l}\beta \text {-carotene } \\
\left(\mu \mathrm{g} 100 \mathrm{~g}^{-1}\right)\end{array}$ & $\begin{array}{l}\text { Total carotenoids } \\
\left(\mu \mathrm{g} 100 \mathrm{~g}^{-1}\right)\end{array}$ \\
\hline 75 & $3.48 \pm 0.45^{\mathrm{a}}$ & $474.90 \pm 17.54$ & $1054.58 \pm 29.58^{\mathrm{a}}$ \\
90 & $3.23 \pm 0.15^{\mathrm{a}}$ & $438.09 \pm 25.49$ & $956.24 \pm 39.07^{\mathrm{b}}$ \\
105 & $3.44 \pm 0.31^{\mathrm{a}}$ & $446.39 \pm 10.81$ & $997.80 \pm 36.62^{\mathrm{ab}}$ \\
120 & $2.59 \pm 0.22^{\mathrm{b}}$ & $415.38 \pm 26.85$ & $939.87 \pm 22.79^{\mathrm{b}}$ \\
\hline
\end{tabular}

$\overline{\mathrm{a}, \mathrm{b}, \mathrm{c}}$ Means within a column with different superscripts are significantly different $(\mathrm{p} \leq 0.05)$

Table 4. RS, Digestible starch (DS), and TS of rice noodle and rice noodle containing different levels of the unripe banana flour

\begin{tabular}{llll}
\hline Substitution level $(\%)$ & RS $(\%)$ & TS $(\%)$ & Non-RS (\%) \\
\hline 0 (control) & $4.21 \pm 0.36^{\mathrm{e}}$ & $74.80 \pm 1.54$ & $70.59 \pm 1.66^{\mathrm{a}}$ \\
20 & $7.33 \pm 0.71^{\mathrm{d}}$ & $75.46 \pm 1.01$ & $68.13 \pm 0.94^{\mathrm{b}}$ \\
40 & $9.19 \pm 0.08^{\mathrm{c}}$ & $75.79 \pm 1.38$ & $66.60 \pm 1.54^{\mathrm{b}}$ \\
60 & $12.83 \pm 0.19^{\mathrm{b}}$ & $76.32 \pm 0.63$ & $63.51 \pm 0.52^{\mathrm{c}}$ \\
80 & $15.45 \pm 0.87^{\mathrm{a}}$ & $75.86 \pm 0.90$ & $60.41 \pm 0.86^{\mathrm{d}}$ \\
100 & $18.64 \pm 0.25^{\mathrm{a}}$ & $76.67 \pm 1.21$ & $58.03 \pm 3.33^{\mathrm{d}}$ \\
\hline
\end{tabular}

Values are means \pm SD of triplicate samples (on a dry weight basis); Values with the same alphabet along the same columns are not significantly different $(\mathrm{p} \leq 0.05)$; Ns: Not significant different at $\mathrm{p}>0.05$

Table 5. Sensorial liking scores (9 point hedonic scale) of rice noodle containing different levels of unripe banana flour

\begin{tabular}{lllllll}
\hline $\begin{array}{l}\text { Substitution } \\
\text { level (\%) }\end{array}$ & Appearance & Color & Flavor (ns) & Texture & Adhesiveness & Overall acceptability \\
\hline 0 (control) & $7.21 \pm 1.29^{\mathrm{a}}$ & $7.29 \pm 1.27^{\mathrm{a}}$ & $6.25 \pm 1.96$ & $7.04 \pm 1.46^{\mathrm{a}}$ & $7.12 \pm 1.0^{\mathrm{a}}$ & $7.17 \pm 1.24^{\mathrm{a}}$ \\
20 & $6.17 \pm 1.52^{\mathrm{ab}}$ & $5.62 \pm 1.69^{\mathrm{ab}}$ & $5.71 \pm 1.65$ & $6.33 \pm 1.63^{\mathrm{ab}}$ & $6.08 \pm 1.79^{\mathrm{ab}}$ & $6.83 \pm 1.37^{\mathrm{ab}}$ \\
40 & $5.83 \pm 1.81^{\mathrm{ab}}$ & $5.46 \pm 1.25^{\mathrm{ab}}$ & $5.38 \pm 1.97$ & $5.79 \pm 2.13^{\mathrm{ab}}$ & $5.75 \pm 1.75^{\mathrm{ab}}$ & $6.00 \pm 1.91^{\mathrm{ab}}$ \\
60 & $6.25 \pm 1.23^{\mathrm{ab}}$ & $5.58 \pm 1.72^{\mathrm{ab}}$ & $6.08 \pm 1.44$ & $6.88 \pm 1.23^{\mathrm{ab}}$ & $6.79 \pm 1.44^{\mathrm{ab}}$ & $6.79 \pm 1.02^{\mathrm{ab}}$ \\
80 & $5.88 \pm 1.36^{\mathrm{ab}}$ & $5.35 \pm 1.96^{\mathrm{ab}}$ & $5.21 \pm 2.04$ & $6.38 \pm 1.74^{\mathrm{ab}}$ & $6.08 \pm 1.56^{\mathrm{ab}}$ & $6.25 \pm 1.54^{\mathrm{ab}}$ \\
100 & $4.96 \pm 1.94^{\mathrm{b}}$ & $4.71 \pm 2.18^{\mathrm{b}}$ & $4.71 \pm 1.94$ & $5.38 \pm 1.74^{\mathrm{b}}$ & $5.50 \pm 2.00^{\mathrm{b}}$ & $5.58 \pm 1.91^{\mathrm{b}}$
\end{tabular}

Values with the same alphabet along the same columns are not significantly different ( $\mathrm{p} \leq 0.05)$; Ns: Not significant different at $\mathrm{p}>0.05$ 


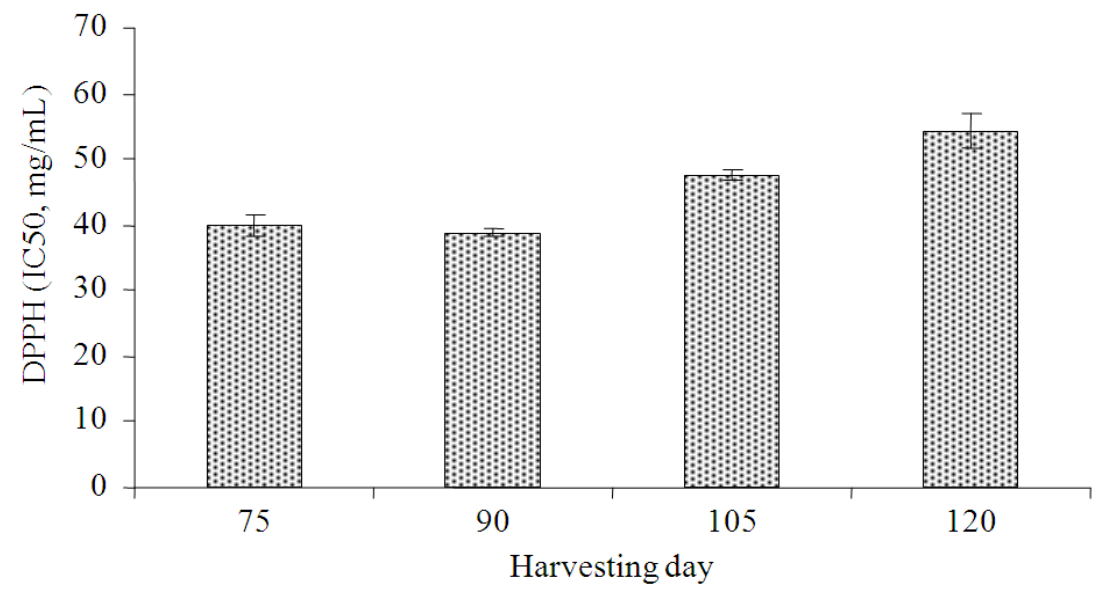

(a)

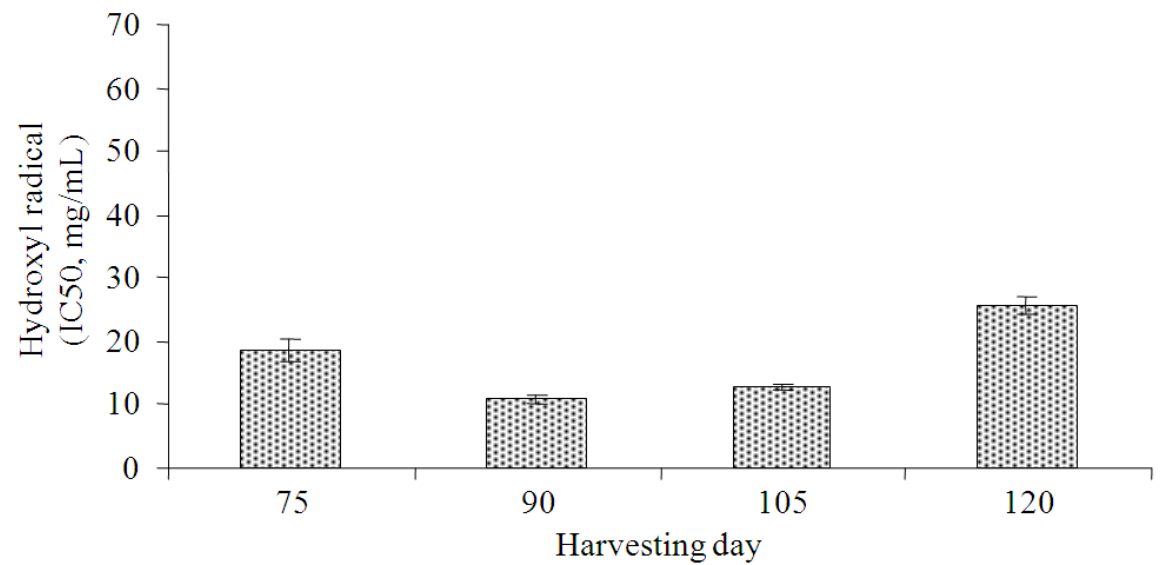

(b)

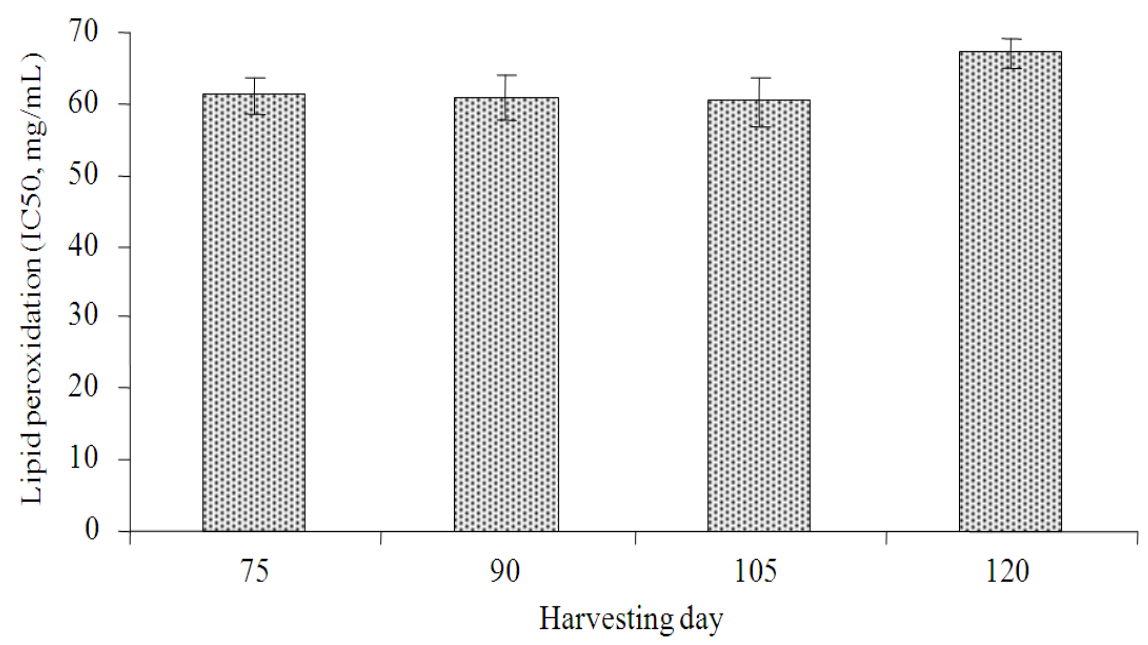

(c)

Fig. 1. Antioxidant activities (DPPH radical scavenging (a), Hydroxyl radical scavenging (b) and Lipid peroxi-dation assay (c)) of unripe banana flours obtained from banana fruits harvested at different maturation days 


\subsubsection{Sensorial Quality}

In the present study, the sensory evaluation of optimally cooked noodles substituted with banana flour was carried out with the objective of choosing the best suited degree of replacement of banana flour (by percentage) for the preparation of the noodles. The means sensory liking scores for appearance, color, flavor, texture, adhesiveness and overall liking of noodles are shown in Table 5. Most panelists scored the noodles substituted with 20 to $80 \%$ banana flour to be similarly acceptable as the control noodles $(0 \%)$ for appearance, color, texture, adhesiveness and overall liking. It was observed that the sensory liking scores of the flavor attributes of noodles were not significantly different with variations in the banana flour content ( 0 to $100 \%$ ). However, in this study, by sensorial acceptance, the substitution of banana flour (20 to 80\%) for rice flour did not affect the acceptance of panelists as shown by significant scores in Table 5. This may due to the sensitivity of the equipment being higher than the threshold of the panelist.

\section{DISCUSSION}

For the Musa sapientum ABB group banana, grown in Thailand, banana fruit at approximately 120 days after bloom will begin the fifth stage according to the $7^{\circ} \mathrm{C}$ color scale (Newilah et al., 2008) or the second stage of ripening after a few days of harvesting. The peel color of banana fruit changed from light green to green with yellow trace on the 120 day as the result of chlorophyll beginning to degrade that gradually exposed carotenoid pigments lying beneath in the unripe fruit. The peel color of banana is an important indicator of the stage of maturity (Newilah et al., 2008).

The total acidity, $\mathrm{pH}$ and reducing sugar of green banana flour in this study were comparable to that studied by Bennett et al. (2010). The starch is converted to sugars as the banana fruit starts to ripen. The type of sugar present in ripe banana includes glucose, fructose and sucrose, among which more than $70 \%$ of the total sugar is sucrose (Marriott et al., 1981). In addition, the sugar content is considered a practicable parameter for evaluation of fruit ripening since it gains good correlation with optical properties and physical properties during ripening (Kader, 1997; Liew and Lau, 2012).

The RS content was decreased due to the maturation stage at 120 days being the second stage of the ABB group banana in which it begins to ripen. Some starches are broken down to simple sugar by several enzymes of carbohydrate hydrolases (Emaga et al., 2007) with the result of lowering the starch content in both RS and TS whilst the content and reducing sugar increases. The results were in agreement with the study of Emaga et al. (2007; Prabha and Bhagyalakshmi (1998).

Total carotenoids and $\beta$-carotene content were slightly lower than the results reported by Newilah et al. (2008) however, the $\beta$-carotene contents were close to the study detailed by Englberger et al., (2006). The variation of carotenoids relied on several factors, especially the cultivars.

For the study on the substitution of unripe banana flour to rice flour in this study, the degree of substitution was higher than the previous studies of Barua and Olson (1998); Ovando-Martinez et al. (2009). The higher level of substitution obtained, in this current study, could be attributed to the addition of $10 \%$ cassava flour as an ingredient. The cassava flour could inhibit the cooking loss and hard texture. The high level of unripe banana flour added resulted in the rice noodle having a higher RS content. Ovando-Martinez et al. (2009), reported that RS values of the sample with banana flour were lower than those reported in spaghetti with banana flour (67.36-69.70\%). Replacing rice flour with unripe banana flour did not affect the TS content of the rice noodle. These results were similar to the TS content in sphagetti prepared from unripe banana flour (72.48-78.90\%) reported by Ovando-Martinez et al. (2009). The instant porridge samples with pre-gelatinized banana flour added were also higher than those of instant rice (Loypimai and Moongngarm, 2013).

The results of liking scores for color in this study differed from our previous study reported by Tiboonbun et al. (2011) who found that the substitution of unripe banana flour for rice flour affected color of rice noodle measured using the Chromameter (Minolta CR300 , Japan). They found that the increasing of the degree of substitution of unripe banana flour significantly increased the $a^{*}$ and $b^{*}$ values of rice noodles and reduced $L^{*}$ values due to the unripe banana flour itself having a dark grey color which was able to be detected using the instrument that might be more sensitive than the panelists. In addition, Tiboonbun et al. (2011) also observed that tensile strength and cooking loss increased when the banana flour content increased.

\section{CONCLUSION}

The study indicated that maturation stage affects RS content, total phenolic compounds and some aspects of 
pasting properties. The banana fruits harvested at 105 days were recommended for preparing the unripe banana flour of the ABB group, as it contained the highest level of RS, carotenoids and had strong antioxidant activity. The substitution of unripe banana flour for rice flour significantly increased RS content of rice noodle without any effect on panelist acceptability. Therefore, the preparation of unripe banana flour and applying it in the preparation of functional food (rice noodle in this study), which is high in resistant starch, is promising and this product is likely beneficial for human health. More investigations on applying the unripe banana to other food products are needed and the limitation of using unripe banana flour would be its color and taste which might affect some quality aspect of some food products.

\section{ACKNOWLEDGEMENT}

The study was financially supported by Mahasarakham University, Thailand, grant number 2554A10902003 and National Research Council of Thailand (NRCT; Graduate Research Grant, 2554)

\section{REFERENCES}

Alkarkhi, A.F.M., S.B. Ramli, Y.S. Yong and A.M. Easa, 2011. Comparing physicochemical properties of banana pulp and peel flours prepared from unripe and ripe fruits. Food Chem., 129: 312318. DOI.org/10.1016/j.foodchem.2011.04.060

AOAC, 2000. Official Methods of Analysis of the AOAC. 17th Edn., Association of Official Analytical Chemists, Arlington, Va, ISBN-10: 0935584242.

Barua, B. and A. Olson, 1998. Reversed-phase gradient high-performance liquid chromatographic procedure for simultaneous analysis of very polar to nonpolar retinoids, carotenoids and tocopherols in animal and plant samples. J. Chromatography B, 707: 69-79. DOI.org/10.1016/s0378-4347 (97) 00614-2

Bennett, N.R., T.M. Shiga, N.M.A. Hassimotto, E.A.S. Rosa and B.R. Cordenunsi et al., 2010. Phenolics and antioxidant properties of fruit pulp and cell wall fractions of postharvest banana (Musa acuminata Juss.) cultivars. J. Agric. Food Chem., 58: 79918003. DOI: $10.1021 /$ jf1008692

Dadzie, B.K. and J.E. Orchard, 1997. Routine Postharvest Screening of Banana/plantain Hybrids: Criteria and Methods. International Network for Banana and Plantain (Inibap), Technical Guidelines. CGIAR, Rome Italy, INIBAP, Montpellier, France, ISBN-10: 2-910810-22-4, pp: 63.
Dasgupta, N. and B. De, 2004. Antioxidant activity of piper betle L. leaf extract in vitro. Food Chem., 88: 219-224. DOI:10.1016/j.foodchem.2004.01.036

Emaga, T.H., R.H. Andrianaivo, B. Wathelet, J.T. Tchango and M. Paquot, 2007. Effects of the stage of maturation and varieties on the chemical composition of banana and plantain peels. Food Chem., $\quad$ 103: 590-600. DOI:10.1016/j.foodchem.2006.09.006

Englberger, L., R.B.H. Wills, B. Blades, L. Dufficy and T. Coyne et al., 2006. Carotenoid content and flesh color of selected banana cultivars growing in Australia. Food Nutrit. Bull., 27: 281-291.

Juarez-Garcia, E., E. Agama-Acevedo, S.G. SáyagoAyerdi, S.L. Rodríguez-Ambriz and L.A. BelloPérez, 2006. Composition, digestibility and application in breadmaking of banana flour. Plant Foods Human Nutrit., 61: 131-137.

Kader, A.A., 1997. A summary of CA recommendations for fruits other than apples and pear. Proceedings of the 7 th International Contr. Atmos. Res. Conference University of California, (CUC' 97), Davis, pp: 34-34.

Kim, K.H., R. Tsao, R. Yang and S.W. Cui, 2006. Phenolic acid profiles and antioxidant activities of wheat bran extracts and the effect of hydrolysis conditions. Food Chem., 95: 466-473. DOI:10.1016/j.foodchem.2005.01.032

Liew, C.Y. and C.Y. Lau, 2012. Determination of quality parameters in Cavendish banana during ripening by NIR spectroscopy. Int. Food Res. J., 19: 751-758.

Loypimai, P. and A. Moongngarm, 2013. Utilization of pregelatinized banana flour as a functional ingredient in instant porridge. J. Food Sci. Technol., DOI: $10.1007 / \mathrm{s} 13197-013-0970-6$

Marriott, J., M. Robinson and S.K. Karikari, 1981. Starch and sugar transformation during the ripening of plantains and bananas. J. Sci. Food Agric., 32: 1021-1026. DOI: 10.1002/jsfa.2740321011

Moongngarm, A. and E. Komphiphatkul, 2011. Germination time dependence of bioactive compounds and antioxidant activity in germinated rough rice (Oryza sativa L.). Am. J. Applied Sci., 8: 15-25. DOI: 10.3844/ajassp.2011.15.25

Newilah, G.N., K. Tomekpe, I. van den Bergh, C. Lusty and E. Akeyampong, 2008. Evaluating bananas and plantains grown in Cameroon as a potential source of carotenoids. Res. Dev., 2: 1773-1778. 
Ovando-Martinez, M., S. Sayago-Ayerdi, E. AgamaAcevedo, I. Goni and L.A. Bello-Perez, 2009. Unripe banana flour as an ingredient to increase the undigestible carbohydrates of pasta. Food Chem., 113:

121-126. DOI:10.1016/j.foodchem.2008.07.035

Prabha, T.N. and N. Bhagyalakshmi, 1998. Carbohydrate metabolism in ripening banana fruit. Phytochemistry, 48: 915-920. DOI: 10.1016/s00319422(97)0093-x

Rodriguez-Amaya, D.B. and M. Kimura, 2004. Harvest Plus Handbook for Carotenoid Analysis. Harvest Plus Technical Monograph Series 2. 1st Edn., International Food Policy Research Institute (IFPRI) and International Center for Tropical Agriculture (CIAT), Washington, DC and Cali, pp: 58.

Rodríguez-Ambriz, S.L., J.J. Islas-Hernández, E. Agama-Acevedo, J. Tovar and L.A. Bello-Pérez, 2008. Characterization of a fibre-rich powder prepared by liquefaction of unripe banana flour. Food Chem., 107: 1515-1521. DOI:10.1016/j.foodchem.2007.10.007
Sakanaka, S., Y. Tachibana, N. Ishihara and L.R. Juneja, 2005. Antioxidant properties of casein calcium peptides and their effects on lipid oxidation in beef homogenates. J. Agric. Food Chem., 53: 464-468.

Somogyi, M.J., 1952. Notes on sugar determination. J. Biological Chem., 195: 19-23.

Suntharalingam, S. and G.G. Ravindran, 1993. Physical and biochemical properties of green banana flour. Plant Foods Human Nutrit., 43: 19-27. DOI: $10.1007 / \mathrm{BF} 01088092$

Tiboonbun, W., M. Sungsri-in and A. Moongngarm, 2011. Effect of replacement of unripe banana flour for rice flour on physical properties and resistant starch content of rice noodle. World Acad. Sci. Eng. Technol., 81: 608-611.

Tribess, T.B., J.P. Hernández-Uribe, M.G.C. MéndezMontealvo, E.W. Menezes and C.C. Tadini et al., 2009. Thermal properties and resistant starch content of green banana flour (Musa cavendishii) produced at different drying conditions. LWT-Food Sci. Technol., 42: 1022-1025. DOI:10.1016/j.lwt.2008.12.017 